\title{
Diabetes Risk Assessment with Blood Parameters of The First Degree Relatives of Patients with Type-2 Diabetes Mellitus
}

\author{
Hatice Demirag ${ }^{1}\left(\mathbb{D}\right.$, Sakine Boyraz ${ }^{2}$ \\ ${ }^{1}$ Gumushane University, Kelkit SHMYO, Emergency and First Aid Program, Gumushane. \\ ${ }^{2}$ Adnan Menderes University, Faculty of Nursing, Internal Medicine Nursing, Aydin. \\ Correspondence Author: Hatice Demirag \\ E-mail: hatice_etbas@hotmail.com \\ Received: 05.12.2019 Accepted: 10.03.2021
}

\begin{abstract}
Objective: This study was conducted to evaluate the diabetes risk in first degree relatives of Type-2 diabetic patients who were not diagnosed with diabetes and test the validity of the Finnish Diabetes Risk Score (FINDRISK) in determining the risk of type-2 diabetes.

Methods: First degree relatives of patients who were hospitalized in "izmir Katip Çelebi University Atatürk Training and Research Hospital", who were not diagnosed with diabetes before, were included in this cross-sectional study. The sample of the research consisted of 200 people determined by power analysis. Data were collected by "a structured question form" and the FINRISK scale. Participants' height, weight, waist circumference were measured by the researcher, and venous fasting blood glucose (FBG) with Glycosylated Hemoglobin (HbA1c) were taken by the researcher.

Results: The average age of the participants was $46.93 \pm 14.83$ (18-86). It was determined that the vast majority of the individuals participating in the study were female (65\%), $63 \%$ were married, $50.5 \%$ received high school or higher education, and $59 \%$ worked in an income-generating job. The findings was indicated that $41.5 \%$ of the participants were in the 'high-risk group' for type-2 diabetes according to the FINDRISK score scale. Sensitivity of FINDRISK score to FBG was $100 \%$ and specificity was $60 \%$.

Conclusion: As a result of findings in this study indicate that It was determined that the risk of DM was high in the first degree relatives of the patients hospitalized with Type-2 DM and the FINDRISK score scale was a good scale in predicting new asymptomatic Type 2 diabetes.
\end{abstract}

Keywords: Risk for diabetes, FINDRISK, type 2 DM, FBG, HbA1c

\section{INTRODUCTION}

The prevalence of diabetes mellitus (DM) for adults worldwide is $8.3 \%$. Although the prevalence of diabetes mellitus (DM) for adults is $7.9 \%$ in European countries, this rate is expected to reach $10.3 \%$ by 2035 (1). Almost half of all DMs in the world are concentrated in the 40-59 age group (184 million). In developing countries, diabetes is mostly seen between the ages of 35-64. Furthermore, DM is identified more frequently among individuals with medium and low incomes (77\%), and the DM rate for this population is expected to increase to $86 \%$ by 2035 as well (1-3).

Such frequency of DM will cause serious complications and early deaths if its treatment and care are not adequately managed. According to the data issued by the International Diabetes Federation (IDF), nearly half of the deaths caused by diabetes worldwide occurred in individuals younger than 70 (1).

Approximately $10 \%$ of all diabetics patients have type-1 DM, while $90 \%$ have type-2 DM. By 2035 , the number of type- 2 diabetes patients is expected to increase by $55 \%$ worldwide $(2,4)$. Adults with a history of DM among their first degree relatives and who are asymptomatic for diabetes are considered to be in the at-risk group for type-2 DM (5). The incidence rate of diabetes in children who have one parent with diabetes is $2-5 \%$ for type-1 DM and $15 \%$ for type-2 DM. However, the incidence rates for children with two diabetic parents is $10 \%$ in type-1 DM and $50 \%$ in type-2 DM (6).

Relieving the social and individual burdens of diabetes, preventing associated complications and minimizing the related death rate is possible only by early diagnosis of this disease and appropriate treatment (7).

Diagnosis, Treatment and Surveillance Guide for Diabetes Mellitus and Its Complications published by the Turkish Endocrinology and Metabolism Association (TEMD) in 2013, includes guidelines for determining which individuals are at risk for Type- 2 diabetes. The guidelines suggest evaluating the answers to the 8 questions developed to determine the 
risk of Type-2 DM using the FINDRISK method. Individuals at risk for diabetes who score more than 20 are required to be included in protection programmes (8). A limited number of studies in Turkey used the FINDRISK Scale in screening studies for the type-2 diabetes, which is frequently observed in adults $(9,10)$.

The present study was conducted to evaluate the diabetes risk in first degree relatives of Type-2 diabetic patients who were not diagnosed with diabetes, to test the validity of the FINDRISK score in determining the risk of type-2 diabetes, and to direct those with high risk to diagnosis.

\section{Research Questions;}

Question 1: According to the Fasting Blood Glucose (FBG) level, can the FINDRISK score be considered a valid scale with which to determine type- 2 diabetes?

Question 2: Are there significant differences between the Glycated Haemoglobin (HbA1c) level and the venous FBG and the FINDRISK score according to gender?

\section{METHODS}

\subsection{Objective}

The research was conducted on first degree adult relatives of in-patients with type-2 DM at the İzmir Katip Çelebi University Atatürk Education and Research Hospital between August 2014 and May 2015.

\subsection{Study Design}

The present study is a complementary and methodological study.

\subsection{Sample and Setting}

The research population comprised type-2 DM inpatients' first degree relatives (mother, father, child, sister) who were not yet diagnosed with diabetes. The number of samples was determined 200 by using power analysis which the error amount was $\alpha=0.05$ and 0.25 with a medium effect size with the power of the targeted test was 0.80 (80\%).

\subsection{Inclusion and Exclusion Criteria}

The inclusion criteria were as follows: First-degree adult relatives of patients with type-2 DM who had not yet been diagnosed with diabetes, those who had no hearing, understanding and speech difficulties, those without cognitive impairment, who agreed to participate in the study, and who could have standing weight and height measurements were included in the study.

Second-degree relatives, underage relatives, unwilling to give blood samples, persons previously diagnosed with diabetes, and relatives who were unable to provide standing height and weight samples were not included.

\subsection{Data Collection}

The study data were collected using a "structured question form" and the "Fin Diabetes Risk Score Scale (FINRISK)", prepared based on the current literature $(2,4,7,8,11,12)$.

The Structured Question Form comprises four sections:

The first section includes eight questions regarding information describing the respondents (age, gender, etc.). The second section includes open - and closed-ended questions to determine the respondents' status regarding type-2 diabetes risk factors [use of cortisone, cholesterol level, medications, etc.]. The third section records the FBG and $\mathrm{HbA} 1 \mathrm{c}$ levels of respondents. Laboratory values are based on the ADA criteria (12) and evaluated as follows: $\mathrm{FBG} \leq 99 \mathrm{mg} / \mathrm{dL}$ and $\mathrm{HbA}_{1} \mathrm{c} \leq 5.6 \%=$ No Risk, FBG $100-$ $125 \mathrm{mg} / \mathrm{dL}$ and HbA1c $5.7-6.4 \%$ = Pre-diabetes, $\mathrm{FBG} \geq 126$ $\mathrm{mg} / \mathrm{dL}$ and $\mathrm{HbA} 1 \mathrm{c} \geq 6.5 \%$ = Diabetes. Blood samples were taken from respondents and delivered to the hospital laboratory by the researcher. All analysis costs were paid by the researcher. The FBG was evaluated by ARCHITECT Brand devices using a multi-constituent calibrator; The $\mathrm{HbA} 1 \mathrm{c}$ was evaluated by ARCHITECT Brand devices calibrated by the Bio-Rad VARIANT-II TURBO haemoglobin test system. In the fourth section, the respondents' anthropometric measures [height, weight, waist size, body mass index (BKI)] were included. Participants' weight measurements were made in an empty room, inside without removing their clothes, and before breakfast, using a conventional scales calibrated by the hospital. The respondents' height (without shoes) and waist size (the narrowest diameter between the arcus costarum and the processus spina iliaca anterior superior) were measured using a non-elastic tape measure.

The FINRISK comprised eight questions (age, BKI, waist size, level of exercise, amount of fruits and vegetables consumed, hypertension status, previous status of blood glucose either at high or limited values, family history of diabetes). The FINRISK was developed by Jaakko Tuomilehto and Jaana Lindström (without laboratory tests to determine individuals with type-2 DM risk) in 1987 and its validity and reliability were analysed in 1992. The FINDRISK scores were evaluated according to Lindström (11), who conducted the reliability and validity study of the scale. The scores for a 10-year, type- 2 diabetes risk were low $=\leq 7$, moderate $=7-11$, medium $=12-14$, high $=15-20$, and very high $=\geq 20$. The minimum and maximum possible scores were 0 and 26 , respectively.

In a number of studies, the breakpoint of the score was determined to be equal to or greater than 15, which determined the validity of the FINDRISK score or the risk of type-2 diabetes $(9,10,13-19)$. In the present study, the breakpoint of the FINDRISK was also determined to be equal to or greater than 15; and such scores were determined to indicate a high or very high risk of type-2 diabetes. 


\subsection{Ethical Consideration}

Before beginning the research, the necessary permission was obtained from the Adnan Menderes University, Faculty of Medicine, Board of Ethics for Non-Invasive Clinical Research (protocol no: 2014/387, serial no: 56989545/050-139) and from İzmir City Southern Public Hospitals Union General Secretariat for ethical considerations relevant to the study. In addition, following the necessary explanations, respondents' verbal consent was received. The question form and the FINDRISK scale were administered by the face-to-face interview method, and anthropometric measurements were completed by the researcher.

\subsection{Statistical Analysis}

Data analysis was conducted on the SPSS 18 package software. Categorical variables were evaluated using Pearson's ChiSquare, the multiple-span-four dimension chi-square test, and Fisher's Exact Test ( $\alpha$-Type error $=0.05$ ).

\section{RESULTS}

This study was conducted on a total of 200 respondents to evaluate the risk of type- 2 diabetes for adult $1^{\text {st }}$ degree relatives of DM inpatients. Of the respondents, $51.5 \%$ had a mother or father with type- 2 diabetes, and $18 \%$ had a sister or brother with type-2 diabetes.

Of the respondents, $65 \%$ were female, $63 \%$ were married, $50.5 \%$ had graduated from high school or a higher institution and $59 \%$ were employed. It was also determined that $90 \%$ of respondents were subject to the social security institution (SSI), and their income covered $65 \%$ of their expenditures (Table 1 ).

Table 1. Distribution of demographical characteristics of respondents $(N=200)$

\begin{tabular}{llcc}
\hline \multirow{3}{*}{ Gender } & & $\mathrm{n}$ & \% \\
& Female & 130 & 65.0 \\
\cline { 2 - 4 } Marital status & Male & 70 & 35.0 \\
& Married & 126 & 63.0 \\
& Single & 74 & 37.0 \\
\cline { 2 - 4 } Education level & Literate or illiterate & 36 & 18.0 \\
& Primary school & 63 & 31.5 \\
& High school and above & 101 & 50.5 \\
Employment status & Employed & 118 & 59.0 \\
& Unemployed & 82 & 41.0 \\
\hline \multirow{3}{*}{ Social security } & Have not & 2 & 1.0 \\
& SSI & 180 & 90.0 \\
& Private health insurance & 12 & 6.0 \\
& Green card & 6 & 3.0 \\
\hline \multirow{3}{*}{ Income level } & Income does not meet expenditures & 64 & 32.0 \\
& Income meets expenditure & 130 & 65.0 \\
& Income greater than expenditures & 6 & 3.0 \\
\hline
\end{tabular}

Age: $46.93 \pm 14.83$ (Min: 18 year, Max: 86 year) Height: $166.5 \pm 7.30$ (Min: $150 \mathrm{~cm}$, Max: $184 \mathrm{~cm}$ ) Weight: $71.47 \pm 12.49$ (Min: 43 kg, Max: $104 \mathrm{~kg}$ ) SSI: social security institution
The mean age of the females in the research group was 44.65 \pm 13.67 , the mean smoking duration was $10.57 \pm 9.03$, the mean FBG value was $96.34 \pm 17.33 \mathrm{mg} / \mathrm{dl}$, the mean $\mathrm{HbA} 1 \mathrm{c}$ level was $5.55 \% \pm 0.58 \%$, the mean $B K I$ value was $25.95 \pm$ $3.11 \mathrm{~kg} / \mathrm{m}^{2}$, the mean waist size was $89.17 \pm 12.57 \mathrm{~cm}$, and the mean FINDRISK score was $13.43 \pm 4.18$.

The mean age of the males in the research group was 51.17 \pm 16.05 , the mean smoking duration was $17.14 \pm 11.46$, the mean FBG value was $97.09 \pm 10.96 \mathrm{mg} / \mathrm{dl}$, the mean $\mathrm{HbA1c}$ level was $5.53 \% \pm 0.4 \%$, the mean BKI value was $25.95 \pm 3.11$ $\mathrm{kg} / \mathrm{m}^{2}$, the mean waist size was $96.97 \pm 8.64 \mathrm{~cm}$, and the mean FINDRISK score was $13.6 \pm 4.71$.

The mean values of the female respondents with regard to their age, smoking duration and waist size variables were significantly lower than the corresponding values of the male respondents $(p<0.05)$.

No statistically significant difference between the mean values of the FBG, $\mathrm{HbA1c}$ and $\mathrm{BKI}$ values of respondents were observed by gender ( $p>0.05$ ) (Table 2 ).

Table 2. Mean values of some diabetes risk factors and indicators of respondents according to gender $(N=200)$

\begin{tabular}{|c|c|c|c|c|c|}
\hline & \multicolumn{2}{|c|}{ Female } & \multicolumn{2}{|c|}{ Male } & \multirow{2}{*}{$\mathbf{p}$} \\
\hline & MeantSD & Min.-Max. & Mean $\pm S D$ & Min.-Max. & \\
\hline Age & $44.65 \pm 13.67$ & $18-78$ & $51.17 \pm 16.05$ & $22-86$ & 0.005 \\
\hline $\begin{array}{l}\text { Smoking } \\
\text { (year) }\end{array}$ & $10.57 \pm 9.03$ & $1-31$ & $17.14 \pm 11.46$ & $2-40$ & 0.018 \\
\hline FBG & $96.34 \pm 17.33$ & $68-225$ & $97.09 \pm 10.96$ & $68-131$ & 0.326 \\
\hline $\mathrm{HbA} 1 \mathrm{c}$ & $5.55 \pm 0.58$ & 4.1-9.9 & $5.53 \pm 0.4$ & $4,6-6,8$ & 0.940 \\
\hline BKI & $25.78 \pm 4.78$ & $\begin{array}{l}16.79- \\
36.99\end{array}$ & $25.95 \pm 3.11$ & $\begin{array}{l}18,94- \\
35,94\end{array}$ & 0.914 \\
\hline $\begin{array}{l}\text { Waist } \\
\text { size }\end{array}$ & $89.17 \pm 12.57$ & $62-125$ & $96.97 \pm 8.64$ & $72-120$ & $0.000 *$ \\
\hline FINRISK & $13.43 \pm 4.18$ & $6-24$ & $13.60 \pm 4.71$ & $5-24$ & 0.863 \\
\hline
\end{tabular}

${ }^{*} p<0.001$

According to the respondents' FINDRISK scores, when type-2 diabetes risk was evaluated, $5 \%$ were classified in the lowrisk group, $28 \%$ were in the moderate-risk group, $25.5 \%$ were in the medium-risk group, $34.5 \%$ were in the high-risk group (diabetes development risk within ten years at 33\%), and $7 \%$ were in the very-high-risk group (diabetes development risk within ten years at 50\%). The respondents' mean FINDRISK scores were $13.49 \pm 4.36$ (Table 3 ).

Table 3. Type-2 diabetes degree of risk and 10-year risk statuses according to the FINDRISK scores of respondents $(N=200)$

\begin{tabular}{ccccc}
\hline Total score & $\mathbf{n}$ & $\%$ & Degree of risk & 10-year risk \\
\hline$(<7)$ & 10 & 5.0 & Low & $(1 \%)(1 / 100)$ \\
$(\mathbf{7 - 1 1 )}$ & 56 & 28.0 & Moderate & $(4 \%)(1 / 25)$ \\
$(\mathbf{1 2 - 1 4 )}$ & 51 & 25.5 & Medium & $(16 \%)(1 / 6)$ \\
$(\mathbf{1 5 - 2 0 )}$ & 69 & 34.5 & High & $(33 \%)(1 / 3)$ \\
$(>\mathbf{2 0})$ & 14 & 7 & Very high & $(50 \%)(1 / 2)$ \\
\hline \multicolumn{5}{l}{ FINDRISK risk score: $\mathbf{1 3 . 4 9} \pm \mathbf{4 . 3 6}$ (Min: $\mathbf{5}$ score, Max: 24 score) } \\
\hline
\end{tabular}


The mean $\mathrm{HbA} 1 \mathrm{c}$ level of the participants was $5.54 \pm 0.52$ (Min: 4.10, Max: 9.90) and the mean FBG values were $96.60 \pm$ 15.37 (Min: 68, Max: 220). According to the diabetes diagnosis criteria published by the ADA (5); according to $\mathrm{HbA} 1 \mathrm{c}$ results, $2 \%$ had diabetes, $38 \%$ had prediabetes; according to FBG results, $3 \%$ had diabetes and $30 \%$ had prediabetes (Table 4 ).

Table 4. Distribution of the HbA1c and the FBG results according to the ADA values of the respondents with respect to the diabetes diagnosis criteria $(\mathrm{N}=200)$

\begin{tabular}{|c|c|c|}
\hline HbA1c ${ }^{*}$ & $n$ & $\%$ \\
\hline Normal $(\mathrm{HbA} 1 \mathrm{c}=5.6 \leq)$ & 120 & 60 \\
\hline Prediabetes $(\mathrm{HbA} 1 \mathrm{c}=5.7-6.4)$ & 76 & 38 \\
\hline Diabetes $(\mathrm{HbA} 1 \mathrm{C}=6.5 \geq)$ & 4 & 2 \\
\hline \multicolumn{3}{|l|}{ FBG* } \\
\hline Normal (FBG = $99 \mathrm{mg} / \mathrm{dl} \leq$ ) & 134 & 67 \\
\hline Prediabetes $(F B G=100-125 \mathrm{mg} / \mathrm{dl})$ & 60 & 30 \\
\hline Diabetes (FBG $=126 \mathrm{mg} / \mathrm{dl} \geq$ ) & 6 & 3 \\
\hline
\end{tabular}

FBG: $96.60 \pm 15.37$ (Min: $68 \mathrm{mg} / \mathrm{dl}$, Max: $220 \mathrm{mg} / \mathrm{dl}$ )

HbA1c: $5.54 \pm 0.52$ (Min: 4.10\%, Max: 9.90\%)

The $\mathrm{HbA1c}$ test must be conducted in laboratories using a method conforming to the International Glycohemoglobin Standardization Program (5). The TEMD does not suggest using the $\mathrm{HbA1c}$ as the sole diagnostic test in Turkey because deficiencies remain in terms of technical equipment, standardization and relevant high costs $(4,8,12,20)$.

The sensitivity and specificity of the FINDRISK scale with regard to the FBG level were $100 \%$ and $60.3 \%$, respectively; the positive predictive value and negative predictive value were $100 \%$ and $7.2 \%$, respectively (Table 5 and Table 6).

Table 5. Sensitivity and Specificity of the FINDRISK Results according to FBG Results

\begin{tabular}{lccc}
\multirow{2}{*}{ FINDRISK } & \multicolumn{2}{c}{ Fasting Blood Glucose } & \multirow{2}{*}{ (FBG) } \\
\cline { 2 - 3 } & Diseased & Healthy & \\
Diseased ( $\geq 15$ score) & $6(100 \%)$ & 77 & $83(41.5 \%)$ \\
Healthy ( $\leq 14$ score) & 0 & $117(60.3 \%)$ & $117(58.5 \%)$ \\
Total & $6(3.0 \%)$ & $194(97.0 \%)$ & $200(100 \%)$ \\
\hline
\end{tabular}

Table 6. ROC analysis results for the prediction power of FINDRISK Scale Results according to FBG Results

\begin{tabular}{lcc} 
& Value & $95 \% \mathrm{Cl}$ \\
\hline Sensitivity & 100 & $54,1-100,0$ \\
\hline Specificity & 60,3 & $53,1-67,2$ \\
\hline+ PV & 7,2 & $2,7-15,1$ \\
\hline -PV & 100 & $96,9-100,0$ \\
\hline AUC & 0,802 & $0,699-0,904$ \\
\hline P & \multicolumn{2}{c}{$<0,001$} \\
\hline
\end{tabular}

In this study, the ROC diagram demonstrates the estimation strength of the FINDRISK score for the Type-2 diabetes status of recently diagnosed patients. These results are presented in Figure 1. The FINDRISK score was calculated at 0.802 (95\% GA: 0.699-0.904), remaining below the ROC diagram plotted to determine the estimation strength of newly diagnosed type-2 diabetes (according to the FBG). The calculated AUC value was determined to be statistically significant $(p<0.001)$. Thus, the FINDRISK score was successful in estimating newly diagnosed type-2 diabetes.

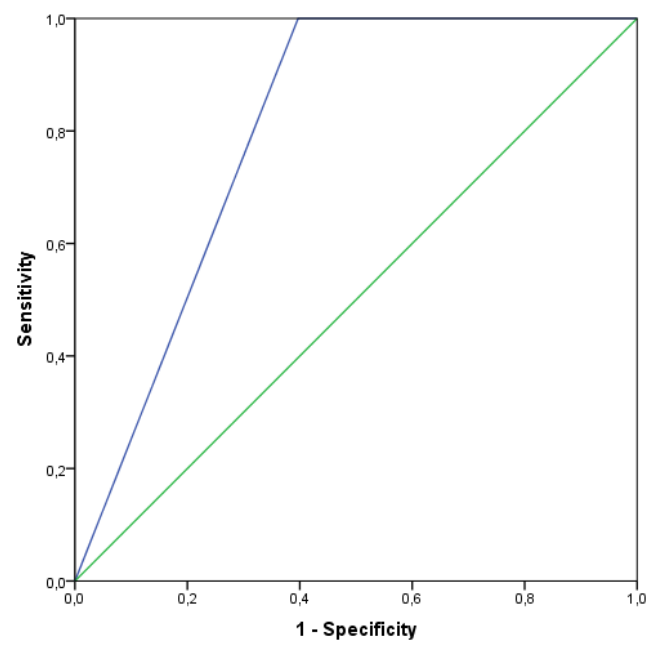

Figure 1. ROC Curve Illustrating the Accuracy of FINDRISC Scores With Respect To FBG Results

\section{DISCUSSION}

The present study was conducted to evaluate the diabetes risk of $1^{\text {st }}$ degree relatives of inpatients previously diagnosed with the type-2 DM. The FINDRISK score was used to identify people at risk for Type 2 diabetes. This tool was developed by Tuomilehto and Lindström in 1992 and adapted into Turkish by the IDF. This scale was determined to be valid for predicting type- 2 diabetes in a number of studies conducted in Finland and numerous other countries. In this study, the FBG was used as the standard, and corresponding results were compared.

The average age of the participants in the study was 46.93 \pm 14.83 (18-86). The average age of women (44.65 \pm 13.67 ) was found to be statistically significantly lower than men (51.17 \pm 16.05 ) (Tables 2 and 5). According to data published by the ADA (12), individuals aged 45 and older are at risk for type-2 DM. According to data published by the WHO (21), type-2 DM is most frequently observed in individuals in the age group of 35-64 in developing countries. Age is reported to be an important risk factor for Type-2 DM and is usually seen in individuals over the age of 40 . However, it has also been reported that the prevalent age of diabetes depends on different life styles; therefore, diabetes can occur in youth or even childhood $(2,7,12,22)$.

In the present study, no significant difference was found between the mean BMI values of women $(25.78 \pm 4.78)$ and men $(25.95 \pm 3.11)$ (Table 2). In the study of Tarı Selçuk (19), it was reported that the average BMI was $27.09 \pm 3.79 \mathrm{~kg}$ / $\mathrm{m} 2$ in men and $28.7 \pm 4.48 \mathrm{~kg} / \mathrm{m} 2$ in women. Costa et 
al. (17) reported that there was no statistically significant difference between men $(28.7 \pm 4.0 \mathrm{~kg} / \mathrm{m} 2)$ and women $(28.9 \pm 4.9)$ in terms of average BMI. Makrilakis et al. (13), the mean BKI values were reported as $29.8 \pm 5.7 \mathrm{~kg} / \mathrm{m} 2$ in women and $29.4 \pm 4.0 \mathrm{~kg} / \mathrm{m} 2$ in men. Bayındır and Çevik et al. (23) reported mean BKI values for females and males at $28.44 \pm 5.94 \mathrm{~kg} / \mathrm{m}^{2}$ and $28.09 \pm 4.11 \mathrm{~kg} / \mathrm{m}^{2}$, respectively. These authors concluded a statistically significant correlation between these values.

Waist circumference values seen as a risk for Type-2 DM are $>88 \mathrm{~cm}$ in women and $>102 \mathrm{~cm}$ in men. In the present study, Females' mean waist size $(89.17 \pm 12.57 \mathrm{~cm})$ was significantly lower than males' ( $96.97 \pm 8.64 \mathrm{~cm}$ ) (Table 2). In the study of Makrilakis et al. (13), it was reported that the average BMI was $29.6 \pm 5.0 \mathrm{~kg} / \mathrm{m} 2$, the average BMI for men was 29.4 $\pm 4.0 \mathrm{~kg} / \mathrm{m} 2$, and the average BMI for women was $29.8 \pm$ $5.7 \mathrm{~kg} / \mathrm{m} 2$. The difference between them was significantly low. Bayındır - Çevik et al. (23) reported a mean waist size of $93.35 \pm 15.72 \mathrm{~cm}$ and $99.38 \pm 12.24 \mathrm{~cm}$ for females and males, respectively; the difference between the two measurements was determined to be significantly low. Costa et al. (17) reported the mean waist size as $93.4 \pm 11.6 \mathrm{~cm}$ in women and $100.0 \pm 10.0 \mathrm{~cm}$ in men. The difference between the two measurements was determined to be significantly low. In the study of Tarı-Selçuk (19), it was reported that the average waist circumference was $99.26 \pm 8.51$, the average waist circumference was $98.59 \pm 8.20 \mathrm{~cm}$ for women, and 100.06 $\pm 8.83 \mathrm{~cm}$ for men. In study of Memiş, Gökçe, Gündoğmuş and Coşkunırmak (10), it was reported that the average waist circumference in women was $79.84 \pm 10.00 \mathrm{~cm}$, and the average waist circumference was $92.93 \pm 12.58 \mathrm{~cm}$ in men.

Toktamış (24) reports that "Individuals are encouraged to quit smoking or at least dramatically reduce the number of cigarettes smoked daily in preventive programmes against type-2 DM". In this study, the mean duration of smoking in women (10.57 \pm 9.03 years) was found to be statistically significantly lower than the average smoking period of men (17.14 \pm 11.46 years) (Table 2$)$.

The ADA (12) addressed Type-2 DM diagnosis criteria for venous $\mathrm{FBG}$ as $<100 \mathrm{mg} / \mathrm{dL}=$ normal, $100-125 \mathrm{mg} / \mathrm{dL}=$ prediabetes and $>125 \mathrm{mg} / \mathrm{dl}=$ diabetes. In this study, no significant difference was found between the mean "venous" FBG of women ( $96.34 \pm 17.33 \mathrm{mg} / \mathrm{dl}$ ) and the mean "venous" FPG of men (97.09 $\pm 10.96 \mathrm{mg} / \mathrm{dl}$ ) (Table 2).

The ADA (12) assessed the HbA1c rate as "<5.7 normal", "5.7 - 6.4 prediabetes" and " $\geq 6.5$ diabetes". In this study, the mean $\mathrm{HbA} 1 \mathrm{c}$ level was measured for females and males at $5.55 \% \pm 0.58 \%$ and $5.53 \% \pm 0.4 \%$, respectively; the difference between them was not significant. The ADA (12) accepts the $\mathrm{HbA1c}$ ratio as <5.7 normal, 5.7-6.4 prediabetes, $\geq 6.5$ diabetes. In this study, no significant difference was found between the mean $\mathrm{HbA} 1 \mathrm{c}$ level of women $(5.55 \% \pm 0.58)$ and the mean $\mathrm{HbA} 1 \mathrm{c}$ level of men $(5.53 \pm 0.4 \%$ ) (Table 2$)$. In the Tari-Selçuk (2013) study, was determined the average HbA1c level of participants was $5.70 \pm 0.81 \%$, the average $\mathrm{HbA} 1 \mathrm{c}$ level of men was $5.62 \pm 0.67 \%$, and the average $\mathrm{HbA} 1 \mathrm{c}$ level of women was $5.77 \pm 0.90 \%$. In another study, Costa et al. (17) reported that there was no statistically significant difference between the average $\mathrm{HbA} 1 \mathrm{c}$ levels by gender.

In this study, the difference between the mean FINDRISK of women $(13.43 \pm 4.18)$ and the mean FINDRISK of men $(13.6 \pm 4.71)$ was not statistically significant (Table 2$)$. In Tarı Selçuk (19), the mean FINDRISK score was $12.22 \pm 4.42$; for females, the rate was $13.68 \pm 3.96$ and for males, $10.49 \pm$ 4.32. In a study by Makrilakis et al. (13), it reported that the participants' mean FINDRISK score was $13.1 \pm 4.9$, and there was no statistically significant difference between the mean FINDRISK score of men $(12.6 \pm 4.9)$ and the mean FINDRISK score of women (13.6 \pm 4.9$)$. In the study of Costa et al. (17), the mean FINDRISK score was $11.8 \pm 4.5$. The rate for females was $12.0 \pm 4.6$ and $11.4 \pm 44$ for males; the mean FINDRISK score for females was significantly higher than for males. In the study of Taşdemir-Koçak, Öncel, Zincir and Seviğ (25) the mean FINDRISK score of the participants was reported 7.57 \pm 0.13 , and in the study of Coşansu, Çelik, Olgun, Özcan and Demir (9) the average FINDRISK score of the participants was reported $7.46 \pm 4.62$.

According to the ADA (5), individuals asymptomatic for diabetes and with first degree relatives diagnosed with DM are considered to be an at-risk group in terms of type-2 DM. Cheta et al. (26) reported that $33 \%$ of diabetic individuals have positive DM history in their families. In the CODIAB (27) study, $66 \%$ of diabetes cases had at least one diabetic relative. In current studies in the relevant literature, positive family history is particularly intensified with mothers as a first degree relative (28-30). In the present study, it was determined that the mother or father of half of the respondents (51.5\%) was diagnosed with type-2 diabetes; brothers or sisters of one-fifth of (18\%) respondents were diagnosed with type-2 diabetes as well. Contrary to the literature in the study of Bayrak, Koç and Suher (29), DM stories were reported in parents $(23.9 \%)$ and siblings $(34.3 \%)$ in the study of relatives of individuals with DM.

According to the respondents' FINDRISK scores, the risk degree for type-2 diabetes was assessed as low for $5 \%$ of respondents, moderate for $28 \%$, medium for $25.5 \%$, high for $34.5 \%$ (risk of developing diabetes within ten years is $33 \%$ ) and very high for $7 \%$ (risk of developing diabetes within ten years is $50 \%$ ) (Table 3 ). In the present study, according to the FINDRISK scores, respondents with scores $\geq 15$ were considered to be "high risk" in terms of type-2 diabetes; respondents with scores $\leq 14$ were considered "low risk". According to this classification, nearly half of the respondents (41.5\%) were "high risk" in terms of type-2 DM; their risk of developing type-2 diabetes within the next 10 years is $33 \%$.

Numerous studies have tested the validity of the FINDRISK score and used those scores to determine the risk of developing type-2 diabetes. Other studies similar to this study used $\geq 15$ as the breaking point of the FINDRISK score (14-16). Hellgren et al. (14) conducted a study on FINDRISK scores (Swedish Version) and determined the type- 2 diabetes risk to be $9.6 \%$. Factors that may have influenced this result 
included a mailing-based response method for the FINDRISK scale, a $56 \%$ response rate, the possibility of biased answers from respondents and the possibility of healthy persons participating in the study. The study of Costa et al. (17), conducted in Spain, reported that $27.0 \%$ of respondents were classified in the high-risk group in terms of type-2 diabetes. In that study, more than half of the respondents were female (66\%), were obese (80\%), and had abdominal obesity (55\%). These findings are consistent with the results of the present study. In study of Coşansu et al (9) was determined low risk of Type-2 diabetes (8.7\%) compared to this study. The reason for this is estimated to be related to the low average age of the participants $(39.35 \pm 10.40)$ and the high rate of men (74.8\%). In a study by Bonaccorsi, Guarducci, Ruffoli and Lorini (18), conducted in Italy, the risk of type-2 diabetes was reported to be $22 \%$. The type- 2 diabetes risk was reported to be $28 \%$ in study of Tarı Selçuk (19). All of these study results reported lower rates than the present study observed. In this study, high type-2 diabetes risk (41.5\%) was associated with the fact that the sample was selected from $1^{\text {st }}$ degree relatives with type-2 DM. According to the results of the FINDRISK score (Greek version) in the study of Makrilakis et al. (13), The high risk of Type-2 diabetes (45\%) supports this research result.

When the $\mathrm{HbA1C}$ and the FBG results of respondents were taken into consideration based on the diabetes-diagnosing criteria published by the ADA (12), according to HbA1c results, $2 \%$ had diabetes, $38 \%$ had prediabetes; according to FBG results, $3 \%$ had diabetes and $30 \%$ had prediabetes. In this study, the mean $\mathrm{HbA} 1 \mathrm{c}$ and FBG scores of respondents were $5.54 \pm 0.52$ (4.10-9.90) and $96.60 \pm 15.37$ (68-220), respectively (Table 4$)$. In national and international studies has been reported that individuals diagnosed based on their $\mathrm{HbA} 1 \mathrm{c}$ scores experienced more metabolic problems than individuals diagnosed based on the FBG or the OGTT $(8,31,32)$. In a national study, the metabolic risk profiles of the respondents classified in the "prediabetes" group based on the $\mathrm{HbA} 1 \mathrm{c}$ (HbA1c 5.7\%-6.4\%) were observed to have deteriorated similar to the risk profiles of the individuals diagnosed with "Combined Glucose Tolerance Disorder" (IFG + IGT) (32). Clearly, using the HbA1c as diagnostic tool to diagnose and treat individuals at risk for complications would help prevent or retard the relevant complications. It is necessary to accelerate studies on the standardization of the $\mathrm{HbA1c}$ test by regulations enacted by the Ministry of Health (31). The HbA1c test is required in laboratories using methods conforming to the International Glycohemoglobin Standardization Program (NGSP) (5). The TEMD does not suggest employing the $\mathrm{HbA} 1 \mathrm{c}$ test alone as a diagnostic tool in Turkey because deficiencies in terms of technical equipment and standardization have not yet been corrected and the associated costs are too high $(4,8,12,20)$. Therefore, the FBG was used as the "golden test" in the present study.

In the present study, the validity of the FINDRISK score was investigated with respect to the venous FBG, one of the diagnostic diabetes tests. The ability of the FINDISK score to predict type-2 diabetes was assessed as an area in the ROC diagram. The AUC [0.802 (95\% GA: 0.699-0.904)] value was determined to be statistically significant, and the FINDRISK score was deemed successful in predicting newly diagnosed type-2 diabetes $(p<0.001) \quad($ Figure 1$)$. Moreover, the sensitivity and specificity values of the FINDRISK scale with regard to the FBG level were $100 \%$ and $60.3 \%$, respectively, and its positive and negative predictive values were $7.2 \%$ and 100\%, respectively (Table 5 and Table 6). In the study of Tarı Selçuk (19), which investigated the reliability and validity of the FINDRISK scale in Turkey, the FINDRISK score was deemed the area remaining in the ROC diagram for estimating newly diagnosed type-2 diabetes and calculated as 0.84 (95\% GA: $0.78-0.89$ ). Makrilakis et al. (13) reported in their study on a Greek population that the FINDRISK score was valid for estimating type-2 diabetes and that estimation strength for newly diagnosed type-2 diabetes was the area remaining in the ROC diagram, calculated as 0.724 ( $\mathrm{Cl}: 0.68-0.76)$.

\section{CONCLUSION}

As a result of this study, indicates that the FINDRISK scale is successful in predicting newly diagnosed type-2 diabetes.

\section{Suggestions;}

-To determine the type-2 diabetes risk for individuals with relatives diagnosed with type-2 DM, the FINDRISK scale may be employed.

-All health employees in primary health care institutions in Turkey, internal medicine-endocrinology physicians and nurses and diabetes nurses could use the FINDRISK scale to determine individuals at-risk for type-2 DM. In addition, individuals diagnosed with type $2 \mathrm{DM}$ in their first degree relatives should also be routinely screened for diabetes risk.

\section{REFERENCES}

[1] International Diabetes Federation (IDF), 2014. Available from: https://www.idf.org/sites/default/files/Atlas-poster-2014_ EN.pdf. (Available date: 25.07.2014).

[2] International Diabetes Federation (IDF), 2013. Available from: http://www.idf.org/signs-and-symptoms-diabetes. (Available date: 19.11.2013).

[3] World Health Organization (WHO). 10 facts about diabetes, 2014. Available from: http://www.who.int/features/factfiles/ diabetes/facts/en/. (Available date: 01.06.2015).

[4] Ulusal Diabetes Kongresi Konsensus Group (UDKK). Diabetes mellitus diagnosis, classification and principles. In: Diabetes Diagnosis and Treatment Guide 2011. page 18-37. (In Turkish)

[5] American Diabetes Association (ADA). Standards of medical care in diabetes-2014. Diabetes Care January 2014; 37(1): S14-S80. doi: 10.2337/dc14-S014.

[6] McPhee ST, Hammur GD. Disorders of the endocrine pancreas. Çoban E, Süleymanlar G, editors. Pathophysiology of Diseases. Ankara: Palme Yayıncılık; 2012. Page 497-522. (In Turkish)

[7] Ministry of Health. Turkey Diabetes Prevention and Control Program 2011-2014 Action Plan for 2011. Available from: http://www.saglik.gov.tr/HM/dosya/1-71375/h/ 
turkiye-diabetes-onleme-ve-kontrol-programi.pdf. (Available date: 24.06.2013). (In Turkish)

[8] Turkey Endocrinology and Metabolism Association (TEMS) Diabetes Mellitus Working and Education Group. Guidelines for diagnosis, treatment of diabetes mellitus and its complications 2020. Page 1-307. ISBN: 978.605.4011-40-7. (In Turkish)

[9] Coşansu G, Çelik SG, Olgun N, Özcan Ş, Demir HG. Determination of factors of Type-2 Diabetes risk factors in adults: an example of a population-based study. 49. National Diabetes Congress; 2013 April 17-21; Antalya: Turkey; 2013. Page 303. (In Turkish) Available from: www.diabeteskongresi2013org. (Available date: 10.12.2013).

[10] Memiş S, Gökçe S, Gündoğmuş EE, Coşkunırmak D. Evaluation of diabetes risks of Health School students with type-2 diabetes in their family. Nursing forum diabetes, obesity and hypertension journal 2017; 6(2): 27-34. (In Turkish)

[11] Lindström J, Tuomilehto J. The diabetes risk score: a practical tool to predict type 2 diabetes risk. Diabetes Care 2003; 26(3): 725-731. DOI: 10.2337/diacare.26.3.725.

[12] American Diabetes Association (ADA). Classification and Diagnosis of Diabetes 2015; 38(1): S8-S16. DOI: 10.2337/ dc15-S005.

[13] Makrilakis K, Liatis S, Grammatikou S, Perrea D, Stathi C, Tsiligros $\mathrm{P}$, Katsilambros N. Validation of the Finnish diabetes risk score (FINDRISC) questionnaire for screening for undiagnosed type 2 diabetes, dysglycaemia and the metabolic syndrome in Greece. Diabetes Metab 2011;37(2): 144-151. DOI: 10.1016/j.diabet.2010.09.006.

[14] Hellgren MI, Petzold $M$, Björkelund C, Wedel $H$, Jansson PA, Lindblad U. Feasibility of the FINDRISC questionnaire to identify individuals with impaired glucose tolerance in Swedish primary care. A cross-sectional population-based study. Diabet Med 2012; 29(12): 1501-1505. https://doi. org/10.1111/j.1464-5491.2012.03664.x.

[15] Cosansu G, Celik S, Özcan S, Olgun N, Yıldırım N, Demir HG. Determining type 2 diabetes risk factors for the adults: $\mathrm{A}$ community based study from Turkey. Prim Care Diabetes 2018; 12(5): 409-415. https://doi.org/10.1016/j.pcd.2018.05.001.

[16] Bayındır Çevik A, Metin Karaaslan M, Koçan S, Pekmezci H, Baydur Şahin S, Kırbaş A, Ayaz T. Prevalence and screening for risk factors of type 2 diabetes in Rize, Nourtheast Turkey: findings from a population-based study. Primary Care Diabetes 2016; 10(1): 10-18. doi:10.1016/j.pcd.2015.06.002.

[17] Costa B, Barrio F, Piñol JL, Cabré JJ, Mundet X, Sagarra R, SalasSalvadó J, Solà-Morales O; DE-PLAN-CAT/PREDICE Research Group. Shifting from glucose diagnosis to the new HbA1c diagnosis reduces the capability of the Finnish Diabetes Risk Score (FINDRISC) to screen for glucose abnormalities within a real-life primary healthcare preventive strategy. BMC Medicine 2013; Feb 21; 11:45: 1-12. DOI: 10.1186/1741-7015-11-45.

[18] Bonaccorsi G, Guarducci S, Ruffoli E, Lorini C. Diabetes screening in primary care: The PRE.DI.CO. study. Ann Ig 2012; 24(6): 527-534. PMID: 23234190.

[19] Tarı Selçuk K. Determination of Type 2 Diabetes Risk in Individuals aged 45-74 in Bigadiç. Dokuz Eylül University. Health Sciences Institute, PhD thesis. 2013. (In Turkish)
[20] Olgun N, Yalın H, Gülyüz Demir H. Diagnosis And Risk Determination Of Diabetes Dealing With Diabetes. Turkish family physician 2011; 2(2): 41-49. (In Turkish)

[21] World Health Organization (WHO), 2013. Available from: http://www.who.int/cardiovascular_diseases/en/. (Available date: 14.05.2015).

[22] Olgun N, Eti Aslan F, Coşansu G, Çelik S. Diabetes mellitus. Karadakovan A, Aslan FE, editors. Care in Internal and Surgical Diseases. Adana: Nobel Medical Bookstore; 2010. Page 829864. (In Turkish)

[23] Bayındır-Çevik A, Karaaslan M, Koçan S, Pekmezci H, Baydur $S$, Kırbaş A, Ayaz T. Prevalence and screening for risk factors of type 2diabetes in Rize, Nourtheast Turkey: findings froma population-based study. Primary Care Diabetes 2015; 10(1):108. doi: 10.1016/j.pcd.2015.06.002.

[24] Toktamış A, Demirel Y. An Independent Risk Factor for Type 2 Diabetes: Smoking. C. Ü. Journal of the Faculty of Medicine 2002; 24 (4): 209-214. (In Turkish)

[25] Taşdemir-Koçak HS, Öncel S, Zincir H, Seviğ Ü. Determination of type 2 diabetes risk ratio and healthy lifestyle behaviors in classroom teachers. Public Health Activities - HASUDER, 16. National Public Health Congress; 2013 October 27-31; Antalya: Turkey; 2013. Page 372. (In Turkish) Available from: http:// www.bingol.edu.tr/documents/16_UHSK.pdf. (Available date: 10.10.2014).

[26] Cheta D, Dimtrescu C, Georgescu M, Cocioabă G, Lichiardopol $\mathrm{R}$, Stamoran $\mathrm{M}$, lonescu-Tîrgovişte $\mathrm{C}$, Păunescu-Georgescu $M$, Mincu I. A study on the types of diabetes mellitus in first degree relatives of diabetic patients. Diabete Metab 1990; 16(1): 11-15. PMID: 2332093.

[27] Thomas F, Balkau B, Vauzelle-Kervroedan F, Papoz L. Maternal effect and familial aggregation in NIDDM. The CODIAB study. Diabetes 1994; 43(1): 63-67. doi: 10.2337/diab.43.1.63.

[28] Bjornholt JV, Erikssen G, Liestol K, Jervell J, Thaulow E, Erikssen J. Type 2 diabetes and maternal family history: an impact beyond slow glucose removal rate and fasting hyperglisemia in low-risk induviduals? Results from 22.5 years of follow-up of healthy nondiabetic men. Diabetes Care 2000; 23(9): 12551259. https://doi.org/10.2337/diacare.23.9.1255.

[29] Bayrak G, Koç E, Suher M. The Prevalence of Diabetes Mellitus Among the Relatives of Type 2 DM Patients, 2004. Available from: http://cms.galenos.com.tr/Filelssue/3/328/ article/2005-1-3.pdf (Available date: 16.10.2015).

[30] Erasmus R.T, Blanco E, Okesina A.B, Mesa Arana J, Gqweta Z, Matsha T. Impmediumnce of family history in type 2 black South Africans diabetic patients. Postgrad Med J 2001; 77: 323-325. (In Turkish)

[31] Turkey Endocrinology and Metabolism Association (TEMS) Diabetes Mellitus Working and Education Group. Guidelines for diagnosis, treatment of diabetes mellitus and its complications 2018. Page 1-254. ISBN: 978.605.4011-32-2. (In Turkish)

[32] Satman I, Omer B, Tutuncu Y, Kalaca S, Gedik S, Dinccag N, Karsidag K, Genc S, Telci A, Canbaz B, Turker F, Yilmaz T, Cakir B, Tuomilehto J; TURDEP-II Study Group. Twelve-year trends in the prevalence and risk factors of diabetes and prediabetes in Turkish adults. Eur J Epidemiol 2013; 28(2): 169-180. doi: 10.1007/s10654.013.9771-5.

How to cite this article: Demirag H, Boyraz S. Diabetes Risk Assessment with Blood Parameters of The First Degree Relatives of Patients with Type-2 Diabetes Mellitus. Clin Exp Health Sci 2021; 11: 151-157. DOI: 10.33808/clinexphealthsci.655688 